GRASAS Y ACEITES 69 (4)

October-December 2018, e280

ISSN-L: 0017-3495

https://doi.org/10.3989/gya.0106181

\title{
Use of the Viscofrit to determine the moment of discarding the thermoxidized beef tallow
}

\author{
N. Segura ${ }^{\bowtie}$, L. de Oliveira, A.Y. Pinchak and M.A. Grompone \\ Área de Grasas y Aceites, Facultad de Química, Universidad de la República. \\ Gral Flores 2124, CP 11800, Montevideo, Uruguay. Tel: ++598 29290707 \\ ${ }^{\square}$ Corresponding author: nsegura@fq.edu.uy
}

Submitted: 15 January 2018; Accepted: 08 June 2018

SUMMARY: Due to the difficulty in determining polar compounds (PC) using the IUPAC method 2.507, simple and low cost devices for in situ determinations, such as Viscofrit, are commercialized for fried food processing establishments. This device is calibrated for oils but not for fats, such as beef tallow, since materials with a high melting point are rarely used worldwide. A large dispersion was observed in the measurements made with Viscofrit at $48{ }^{\circ} \mathrm{C}$ on thermoxidized beef tallow. The maximum emptying time was reached at about 6 hours of thermoxidation, at which point the fat still does not reach the maximum PC level allowed. In this test, a great dispersion in the data and a high percentage of "false values" were observed, which may be due to the presence of fatty solids at the measurement temperature, which affect the emptying time. In order to use Viscofrit for fats, such as beef tallow, it is suggested to perform a calibration at a temperature outside the range established by the manufacturer which ensures the absence of fatty solids, in this case $60^{\circ} \mathrm{C}$. Under these conditions, a maximum emptying time of 37 seconds was obtained.

KEYWORDS: Beef tallow; Frying; Polar compounds; Viscofrit

RESUMEN: Uso del Viscofrit para determinar el momento de desechar la grasa vacuna termoxidada. Debido a lo dificultosa de la determinación de compuestos polares (PC) por el método IUPAC 2.507 se comercializan dispositivos sencillos y de bajo costo como el Viscofrit, para determinaciones in situ en los locales elaboradores de alimentos fritos. Este dispositivo está calibrado para aceites y no para grasas, como la grasa vacuna, ya que el uso de estos materiales con alto punto de fusión es de uso poco frecuente a nivel mundial. Se observó una gran dispersión en las medidas realizadas con el Viscofrit a $48^{\circ} \mathrm{C}$ sobre la grasa vacuna termoxidada. El máximo de tiempo de vaciado se alcanzó a unas 6 horas de termoxidación, tiempo al que la grasa aún no alcanza el nivel de PC máximo admitido. En este ensayo se observó una gran dispersión en los datos y un alto porcentaje de "valores falsos", lo que pudo deberse a la presencia de sólidos grasos a la temperatura de medida que afectan el tiempo de vaciado. Con el fin de utilizar el Viscofrit para grasas, como la grasa vacuna, se sugiere realizar una calibración a una temperatura fuera del rango establecido por el fabricante que asegure la ausencia de sólidos grasos, en este caso $60^{\circ} \mathrm{C}$. En estas condiciones se obtuvo un tiempo máximo de vaciado para la grasa vacuna de 37 segundos.

PALABRAS CLAVE: Compuestos polares; Fritura; Grasa vacuna; Viscofrit

ORCID ID: Segura N https://orcid.org/0000-0002-9196-1557, Oliveira L de https://orcid.org/0000-0001-8874-0262, Pinchak AY https://orcid.org/0000-0002-7230-886X, Grompone MA https://orcid.org/0000-0002-3306-804X

Citation/Cómo citar este artículo: Segura N, Oliveira L de, Pinchak AY, Grompone MA. 2018. Use of the Viscofrit to determine the moment of discarding thermoxidized beef tallow. Grasas Aceites 69 (4), e280. https://doi.org/10.3989/ gya.0106181

Copyright: (C2018 CSIC. This is an open-access article distributed under the terms of the Creative Commons Attribution 4.0 International (CC BY 4.0) License. 


\section{INTRODUCTION}

Beef tallow (BT) is a sub-product of the meat industry, and therefore it is a fatty material of high availability and relative low cost since it represents a very high percentage of the production of fats and oils in Uruguay. Traditionally it has been destined to the food industry. This fatty material presents a significant amount of saturated fatty acids which in principle gives it a high stability against thermoxidation, which makes it a good means for frying.

Worldwide, vegetable oils are normally used for frying food, but in the Río de la Plata area, BT is traditionally used for this purpose, particularly for cooking "tortas fritas" and "pastelítos dulces", to which it gives a special flavor which is highly appreciated by consumers. The sale and preparation of these products is usually homelike or artisanal (Grompone, 2010).

In studies conducted by Pinchak et al., (2013) it is shown that BT has a variable thermoxidative behavior that depends on its manufacturer; and if it receives adequate treatment, this fatty material can be a good frying medium.

The repeated use of beef tallow for frying, as for other fatty materials, leads to the formation of polar compounds (PC) and polymers. Many countries have regulations which set limits on their contents, and these limits determine the time of discarding. Uruguay has legislation dating back to 2012 regarding the conditions that an oil or fat for frying must satisfy and establishes that the content of PC must be less than $25 \%$.

As the determination of PC by the IUPAC 2.507 method is laborious, lengthy and requires suitable staff, simple and relatively low cost devices are commercialized for in situ determinations in fried food processing establishments. Among them is the Viscofrit method, which consists of a small cone of stainless steel with a small calibrated hole at its bottom. The test is based on the time necessary to empty the cone filled with the frying oil. The cone is emptied by gravity through a hole. The test gives response to the increase in viscosity due to the formation of polymerization compounds. (Marmesat et al., 2007) The instrument is equipped with a graduated thermometer for temperatures between 15 and $50{ }^{\circ} \mathrm{C}$ and another scale with the maximum emptying time from which the oil must be replaced (www.Viscofrit.com, Castellón-Arnau, 1999).

The problem with using commercial devices is that they are not calibrated for BT but for oils, since $\mathrm{BT}$ is rarely used worldwide.

The aim of this work is show the difficulties in the use of the Viscofrit to determine the discarding moment of thermoxidized BT or other fats with high melting points. It also suggests carrying out measurements at higher temperatures than those recommended by the device supplier as a possible solution.

\section{MATERIALS AND METHODS}

\subsection{Raw material}

Uruguayan refined beef tallow was used. The BHT added is declared as an antioxidant on the package label.

\subsection{Thermoxidation of beef tallow whithout food}

$600 \mathrm{~g}$ of BT were placed in a Pyrex Bohemian glass and thermoxidized on a heating plate at 180 $\pm 5{ }^{\circ} \mathrm{C}$ for one hour and with slow agitation by a magnetic stirrer. The heating time to reach the test temperature was approximate 30 minutes. The surface/volume ratio of the fat in the glass was 0.087 $\mathrm{cm}-1$. Heating took place in the presence of air and absence of food.

A sample of about one gram was withdrawn after each hour of heating to determine the percentage of polar compounds according to the modified standard IUPAC 2.507 method and a measurement was made with the Viscofrit equipment without the need to take a sample as the measurement was made directly inside the thermoxidation glass. The surface/volume ratio of fat was not affected during the test since the intakes were very small in relation to the mass of material used. The thermooxidated samples were stored at $-20{ }^{\circ} \mathrm{C}$ until analysis.

\subsection{Determination of the total content of polar compounds (Standard method IUPAC 2.507 modified)}

The procedure of standard method IUPAC 2.507 was carried out, but the quantity of sample and the corresponding volumes of reagents were decreased in accordance with the original method. The modification was made by comparing the results with those of the unmodified method.

$300 \mathrm{mg}$ of fat were weighed and diluted in the minimum amount of the elution mixture (petroleum ether: diethyl ether 90:10 v / v). The sample was placed in a filtration column $(20 \mathrm{~mL}$ with septum, SUPELCO) prepared with $6.3 \mathrm{~g}$ of silica gel (dried at $160{ }^{\circ} \mathrm{C}$ for 4 hours, with water content adjusted to $5 \%$ ). The non-polar fraction was eluted with $65 \mathrm{ml}$ of the elution mixture to a balloon. The fraction of polar compounds was then eluted with $50 \mathrm{~mL}$ of diethyl ether to a second balloon. The solvents were removed with a roto evaporator until constant weight.

The analysis was performed in triplicate and the average and standard deviation were calculated. 


\subsection{Analysis of the quality of thermoxidized beef tallow by the Viscofrit device}

\subsubsection{Determination of the emptying time of the Viscofrit at $48^{\circ} \mathrm{C}$}

The Viscofrit system includes two interchangeable thermometers with different time scales for emptying time, each one calibrated for one of the two main groups of oils usually used in frying: the "oleic type" thermometer, mostly used for monounsaturated fatty acid mostly; and the "linoleic type" thermometer, used mostly for polyunsaturated fatty acid.

The measurements were taken at $48{ }^{\circ} \mathrm{C}$, a condition within the measurement range of the equipment, but above the range recommended by the manufacturer $\left(20-30{ }^{\circ} \mathrm{C}\right)$, due to the high melting point of the beef tallow. For this test, the "oleic type" thermometer was selected, taking into account the high content of saturated and monounsaturated fatty acids in BT (Pinchack et al., 2013, Segura et al., 2011).

\subsubsection{Determination of the emptying time of the Viscofrit at $60^{\circ} \mathrm{C}$.}

In order to ensure a constant temperature of the fat during measuring, the glass containing the thermoxidized fat was placed in a water bath at $60{ }^{\circ} \mathrm{C}$. The emptying times of the equipment were measured in triplicate, and the average and standard deviation were calculated.

\section{RESULTS AND DISCUSSION}

Monitoring the thermoxidation of beef tallow was carried out in the first instance by measuring its deterioration with the Viscofrit according to the manufacturer's specification (Test 1); and then in the conditions that the authors considered would improve the shortcomings found with this method (Test 2).

\subsection{Test 1: Use of the Viscofrit according to the manufacturer's specification for beef tallow}

Figure 1 (Test1) shows the variation in PC content as a function of thermoxidation time. After 14 hours of thermoxidation, a content of $25 \%$ PC was reached (maximum allowed by the Uruguayan legislation). For thermoxidation times longer than 14 hours, the BT should be discarded. At less than 14 hours of thermoxidation, the BT complies with the requirements of the legislation.

Figure 2 shows the results obtained for the emptying time of Viscofrit at $48{ }^{\circ} \mathrm{C}$ for thermoxidized BT. The maximum time limit for emptying the Viscofrit for oils of the "oleic type", indicated by the manufacturer for measurements at $48{ }^{\circ} \mathrm{C}$ is 39 seconds, which is reached at about 6 hours of thermoxidation of the BT (indicated in this graph by a full line). The maximum PC allowed by the Uruguayan legislation is $25 \%$, corresponding to 14 hours of thermoxidation (indicated in this graph by a dotted line).

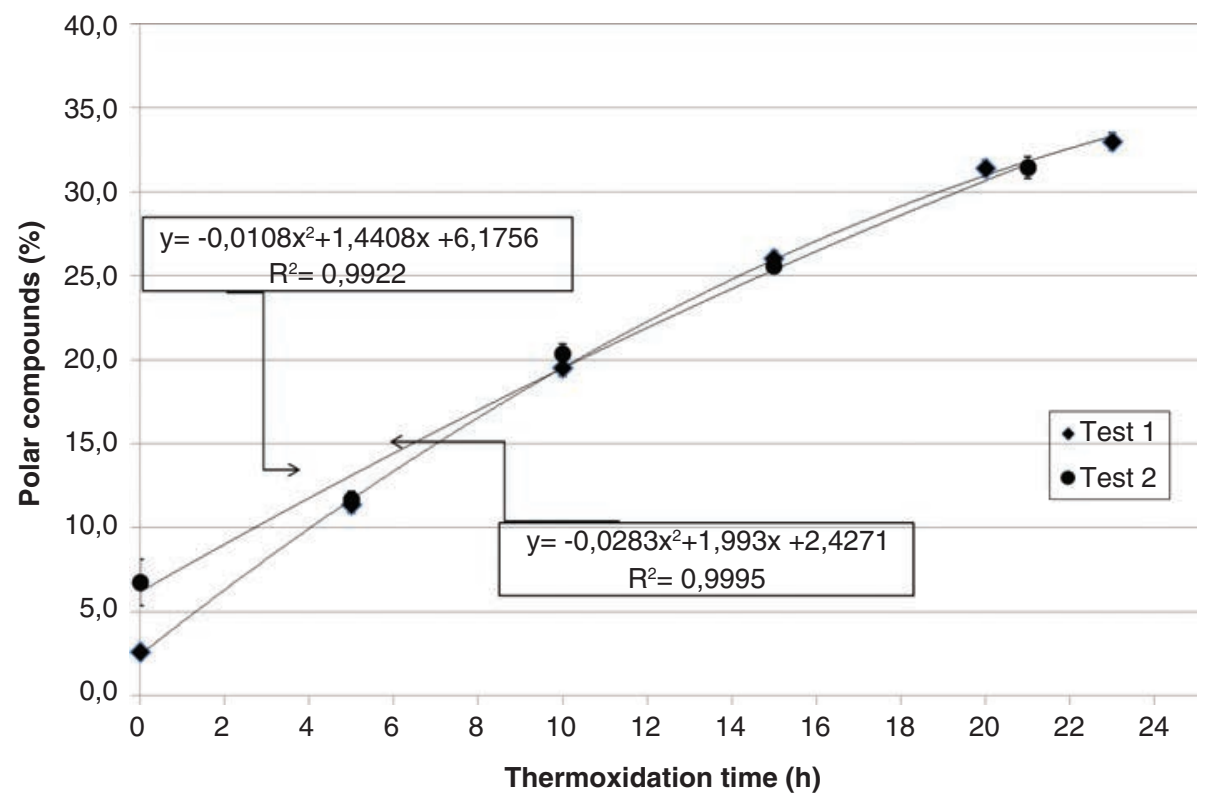

FIGURE 1. Variation of polar compounds as a function of thermoxidation time. Test 1: thermoxidation of beef tallow with the use of the Viscofrit according to the manufacturer's specification Test 2: thermoxidation of beef tallow with the use of the Viscofrit at $60{ }^{\circ} \mathrm{C}$. Measurement made in triplicate. 


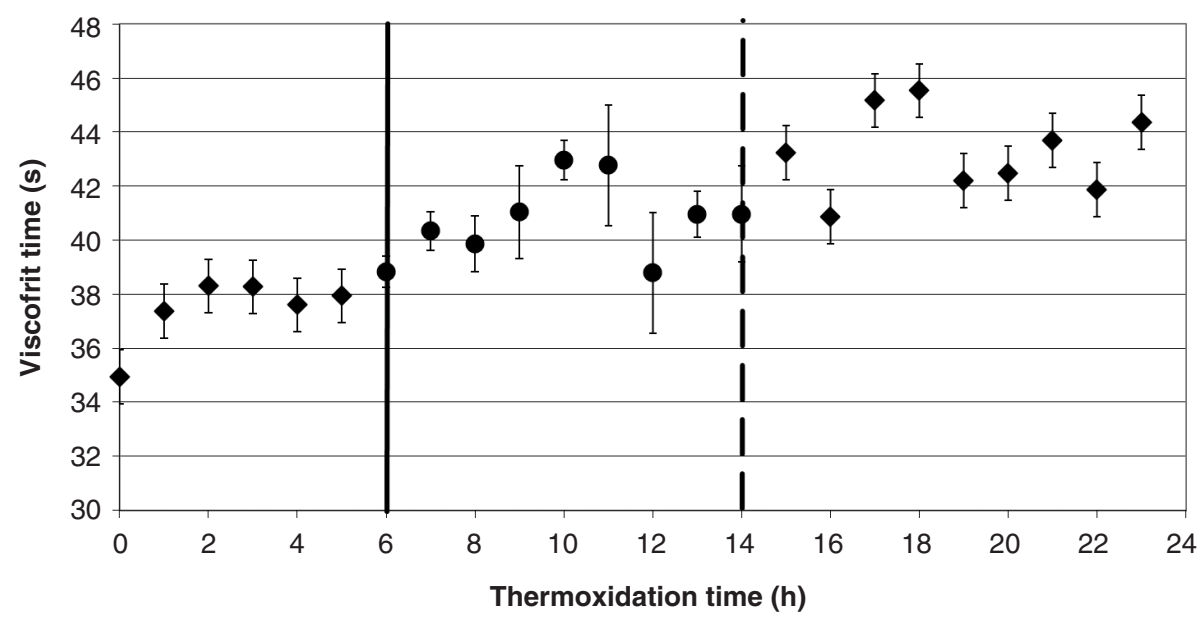

Figure 2. Average Viscofrit emptying times measured at $48^{\circ} \mathrm{C}$ as a function of the thermoxidation time of BT. Measurement made in triplicate.

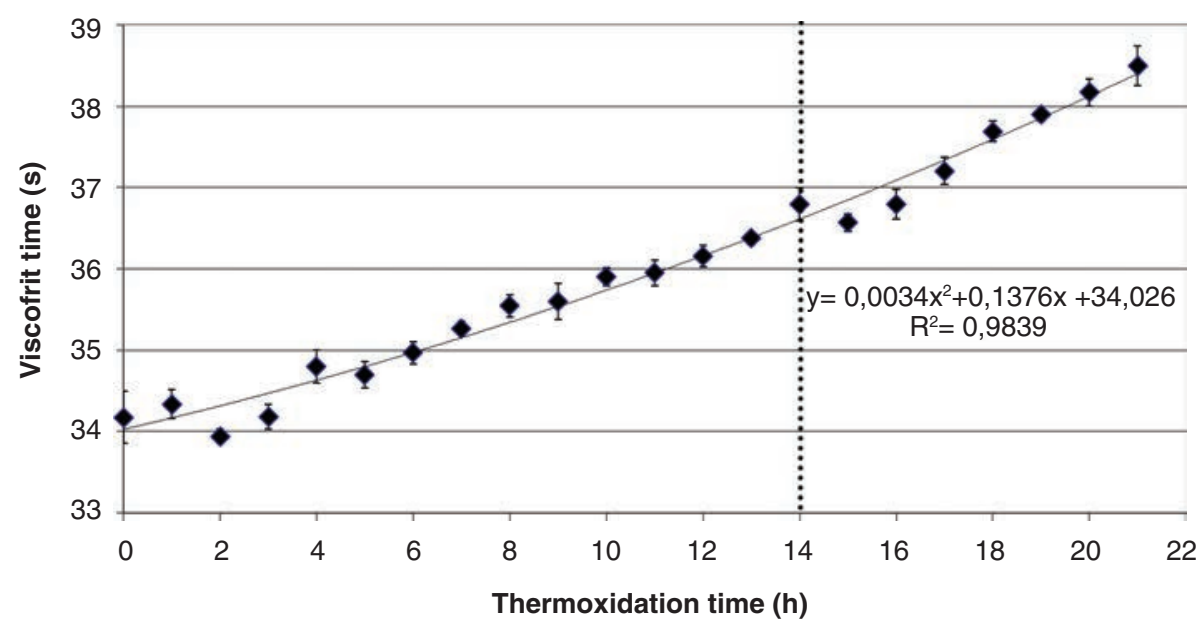

Figure 3. Average Viscofrit emptying times measured at $60{ }^{\circ} \mathrm{C}$ as a function of the thermoxidation time of BT. Measurement made in triplicate.

All points with circle markers correspond to a $\mathrm{PC}$ content of less than $25 \%$ but with higher emptying times than 39 seconds, that is, they indicate "false positives". This means that about 9 measurements (out of a total of 23) gave incorrect results. On the other hand, 5 measurements (out of a total of 6), corresponding to lower thermoxidation times than 6 hours, gave emptying times which were very close to the maximum allowed of 39 seconds, when, in reality, they contained between 5 and $12 \%$ of PC. As a consequence, according to these measurements in the Viscofrit, these samples would be about to be discarded when, in reality, they contained a low percentage of PC.

However, the results showed that there was no significant difference for the thermoxidation times from 0 to 6 hours nor between 6 to 14 hours ( $p>$ 0.05 ). Given such dispersion between the values, it was found that for the emptying time corresponding to 6 hours, 6 of the 14 measurements were significantly different, showing the presence of several false values, positive and negative. Considering what was just discussed proves that the Viscofrit device used is not the most convenient device for the determination of the discarding of beef tallow.

In conclusion, the measurements made with the Viscofrit at $48{ }^{\circ} \mathrm{C}$ in thermoxidited BT are unreliable given the frequency of erroneous results, and considering the limit emptying time of 39 seconds.

Possibly the problem lies in that the temperature is too low for this type of fatty material. According to Grompone (1989) the melting point measured in open capillary (slip point) of the Uruguayan BT varies between $45^{\circ} \mathrm{C}$ and $48^{\circ} \mathrm{C}$. Therefore, at $48^{\circ} \mathrm{C}$ the BT can contain a certain amount of crystals (even if they were small) since they are not completely fused. 
If these fats contain thermoxidation compounds (especially polymers), the solid contents at this temperature could be higher.

The presence of solids would increase the viscosity of the fat (these crystals could partially obstruct the Viscofrit hole) and, consequently, they would increase the emptying time of the Viscofrit. This could be a possible explanation as to why samples with false results have higher emptying times than expected.

\subsection{Test 2: Determination of the emptying time of the Viscofrit at $60^{\circ} \mathrm{C}$ for beef tallow}

To solve the observed problem, a temperature of $60{ }^{\circ} \mathrm{C}$ was selected for measurement with Viscofrit, which ensured the absence of fat solids in the material. At this temperature, a second monitoring of the Viscofrit emptying time was performed as a function of the thermoxidation time of a fresh BT (Figure 3). At the same time, samples were taken to later determine the $\mathrm{CP}$ content as a function of the thermoxidation time in this new study (Figure 1, Test 2).

It was observed that in this test the BT also reached $25 \%$ of $\mathrm{CP}$ in around 14 hours. Considering this and the emptying times registered (Figure 3), the emptying time at $60^{\circ} \mathrm{C}$ which sets the BT discarding would be 37 seconds.

In this case it is also observed that there are emptying times close to discard that could generate "false positives". If a 0.5-1 second error is considered in the measurement of the emptying time, the "false positives" could be generated after 10 hours of thermoxidation, with a CP content above $20 \%$. This value, although it is lower than the value established by the legislation and implies the discarding of the fatty material, would not harm the food processor too much since the deterioration of the fat is already substantial and from the point of view of the health of the consumer this, in reality, is beneficial.

No significant difference was found for the thermoxidation times from 13 to 16 hours, suggesting the presence of false positives. As for the false negatives, they appeared for the thermoxidation times from 14 to 17 hours, considering that no significant difference was found $(p>0.05)$ between the emptying times for the corresponding thermoxidation hours. Both types of falses are very close to the discarding limit, with $\mathrm{CP}$ values ranging from 20 to $27 \%$.

\section{CONCLUSIONS}

The Viscofrit could not be used for BT within the temperature range established by the manufacturer. However, if the measurement is made at $60{ }^{\circ} \mathrm{C}$, it is possible to use this device using a discard criteria like the one reported in this work.

\section{ACKNOWLEDGMENTS}

The authors thank the PEDECIBA (Programa de Desarrollo de las Ciencias Básicas) for their financial support.

We would like to especially recognize Dra. María Antonia Grompone for her invaluable contributions, advice and motivation. RIP

\section{REFERENCES}

Castellón-Arnau A. 1999. Dispositivo medidor de la alteración de aceites comestibles recalentados. Patent ES 1043 160U.

Decreto $N^{\circ} 291 / 012$ de 30/08/2012. Modificación del Reglamento Bromatológico Nacional 315/994. Uruguay. (http://www. impo.com.uy/bases/decretos-reglamento/291-2012)

Grompone MA. 1989. Physicochemical properties of fractionated beef tallows. J. Am. Oil Chem. Soc. 66, 253-255. https://doi.org/10.1007/BF02546070

Grompone MA. 2010. Properties and uses of beef tallow. In: Tomás M. C. (Ed.). Advances in Fats and Oils Research. Transworld Research Network, India, pp. 165-178. ISBN13: $978-8178954721$

IUPAC 1992. International Union of Pure and Applied Chemistry. Standard methods for the analysis of oils, fats and derivatives, 7th Edition. Ed.: Pergamon Press, Oxford.

Marmesat S, Rodriguez E, Velasco J, Dobarganes C. 2007. Quality of used frying fats and oils: comparison of rapid test based on chemical and physical oil properties. Int. J. Food Sc. Techn. 42, 601-608. https://doi. org/10.1111/j.1365-2621.2006.01284.x

Pinchak Y, Merlinski N, Pardo MJ, Grompone MA. 2013. Study of the stability of beef tallow at high temperatures and comparison with other fatty materials. J. Food Sci. Engin. 3, 430-434.

Segura N, Claro da Silva R, Schäfer de M. Soares FA, Gioielli LA, Jachmanián I. 2011. Valorization of Beef Tallow by Lipase-Catalyzed Interesterification with High Oleic Sunflower Oil. J. Am. Oil Chem. Soc. 88, 1945-1954. https://doi.org/10.1007/s11746-011-1876-y 